\title{
Algunos aspectos de la vida y la poesía de Pero Guillén de Segovia
}

\author{
Carlos Moreno Hernández \\ Colegio Universitario de Soria \\ (Universidad de Valladolid)
}

Pretende este trabajo completar y precisar otro anterior ${ }^{1}$ en el que se enmarcaba la vida y la obra de Pero Guillén en el contexto histórico y literario de mediados del siglo $\mathrm{XV}$, desde finales del reinado de Juan II hasta la muerte de Enrique IV.

$\mathrm{Al}$ analizar el probable origen converso del autor se apuntaba en el trabajo citado su posible vinculación a la familia conversa segoviana de los Arias, quienes pudieron haberle socorrido en su época de caída en desgracia, entre la muerte de Álvaro de Luna en 1453 y su entrada en la casa del arzobispo de Toledo, Alfonso Carrillo, en 1463, período al que debe corresponder su residencia «allende Pedraza bien cerca la sierra», tal como el autor declara en su primera suplicación a Carrillo ${ }^{2}$,

1 «Pero Guillén de Segovia y el círculo de Alfonso Carrillo», en Revista de Literatura, 94, 1985, pp. 17-49.

2 «Dezir que fizo Pero Guyllén, dyrygido o difirydo al señor arçobispo de Toledo sobre la cayda de su estado del dicho Pero Guyllén», en el Ms. 2763 (siglo XV) de la Biblioteca de la Universidad de Salamanca, folios 74v.-78v., verso 436 . La obra se encuentra también en dos copias del siglo XVIII de otros manuscritos perdidos (Mss. 4114 y 3742 de la Biblioteca Nacional), conteniendo 30 estrofas más que la versión del Ms. 2763 (vv. 41-280). 
compuesta para que éste le ayudase y que no tuvo el efecto deseado, por lo que le escribe una segunda suplicación en la que detalla:

Ventura y fortuna mostrando el rebés falléme en Segovia con sobra denojos

bien cerca las casas del noble marqués.

Estando así triste, con poca alegría pensando mis daños mis cuitas y males, falléme en mi falda doscientos reales con que me pensaba pasar algún día, mas como de ante prestado comía por no los perder, queriendo escondellos vi tantas manos y priesa sobre ellos que luego sentí mi falda vacía ${ }^{3}$.

En relación con esto es muy significativa la distinción que aparece en el Libro llamado el Alboraique, escrito hacia 1488, entre los conversos de Castilla la Vieja y los del reino de Toledo, Andalucía, Murcia y Extremadura, considerando en general a los primeros sinceros y a los otros no ${ }^{4}$. Segovia sería un refugio más seguro que Toledo o Sevilla, ciudad de la que Pero Guillén procedía. Scholberg, al referirse al prototipo del funcionario converso que aparece en la sátira anticonversa de mediados de siglo titulada «Traslado de una carta de privilegio que el rey Don Juan II dio a un hidalgo», relacionada con las matanzas de Toledo en 1449, cita un pasaje en el que aparece un converso en la iglesia,

llevando, en lugar de oras o psalterio, el libro de memoria de las rentas o alcavalas que tenedes arrendadas a vuestro cargo, fingiendo que rezáis los psalmos penitenciales ${ }^{5}$.

Guillén debió de ejercer como arrendador en la época de Álvaro de Luna, o al menos viviría de algún cargo relacionado con la contaduría real, como se deduce, entre otras cosas, de su posterior ocupación principal de contador mayor en la casa de Carrillo, y además escribió unos Salmos Penitenciales en los que afirma muy seriamente la sinceridad de su fe, algo de lo que no puede dudarse al examinar su obra con

3 «Segunda suplicación que fizo Pedro Guillén de Sebilla al señor Dn. Alfonso Carrillo, Arzobispo de Toledo, por que de la primera non obo aquel efecto que della esperaba», en el Ms. 4114 de la Nacional, fols. 24r.-48r., versos 565-576.

4 Kenneth R. Scholberg, Sátira e invectiva en la España medieval, Madrid, Gredos, 1971, pp. 352-3. Rafael Alemany, «Acerca del supuesto origen converso de Alfonso de Palencia», en Estudi General, Gerona, 1, II (1981) pp. 35-40.

5 Scholberg, op. cit., p. 351. 
detalle, así como su pertenencia al círculo arzobispal desde 1463, donde las ideas de base estoico-paulina, a la búsqueda de un cristianismo más auténtico, son predominantes. Por otro lado, en una composición probablemente escrita en su época de desgracia se contiene una alusión a la recaudación en la que se previene contra la falta de honradez en este oficio, so pena de acabar en el calaboço, tema de la obra ${ }^{6}$.

La coherencia de Guillén en su trayectoria vital e ideológica aparece por todas partes, sobre todo en relación con la idea de la inseparabilidad de la religión, o la ética, y la política, y la creencia en la necesidad de una monarquía fuerte que supere los enfrentamientos civiles y religiosos de la época, algo que se encuentra ya antes en Juan Alfonso de Baena y en Juan de Mena, tal como señala Márquez Villanueva al referirse al Decir a Juan II del primero y al Laberinto de Fortuna del segundo:

The country is seriously ill, according to Baena, and urgently needs a combination of both harsh and soothing medicines that only its chief physician, the King, can administer, with don Alvaro de Luna as a technical executor [...] It is, with only minor differences, the same political dream that Juan de Mena articulates in his Laberinto ${ }^{7}$.

Este ideal es evidentemente heredado por Pero Guillén, aunque había ya comenzado a deteriorarse tras la caída de Álvaro de Luna, que supuso un gran golpe para Juan de Mena, haciéndole desembocar en el ascetismo y la piedad íntima, tal como se muestra en su última obra, las Coplas contra los pecados mortales, que dejó inacabadas a su muerte en 1456 y que fueron continuadas por Pero Guillén y Gómez Manrique. Es significativo que sea Guillén uno de los pocos autores de su época que se atreve a defender a Álvaro de Luna en el decir que dedica a la muerte de condestable, en el que aparece además una velada acusación al rey:

Pues el syervo es obligado

al señor con obidençia, sy en algo fue culpado non niego la consecuençia ${ }^{8}$.

6 «Dezir que fizo Peró Guyllén sobre los milagros del calaboço», en el Ms. 2763, fols. 77r.-78v., versos 105-112: «Este quiere que las rentas / se recauden sin maliçia / [...] / no consiente que las qüentas/se fenezcan por engaño...»

7 Francisco Márquez Villanueva, «Jewish fools of the Spanish fifteenth century», en Hispanic Review, 50, 1982, p. 401.

8 Ms. 2763, fols. 55r.-56v, vv. 117-120. 
Poco después, con la llegada al trono de Enrique IV, Guillén escribe otro decir al nuevo monarca, que puede fecharse entre 1455 y 1457 , período de esperanza todavía, en donde apunta el deseo de unidad nacional y proyecta sobre el rey el mesianismo que luego, tras la frustración, será trasladado a Isabel y Fernando, poniéndole como ejemplo a su abuelo y no a su padre, Juan II:

\section{Por ende roguemos la faz por el suelo a dios que lo dexe bevir e reynar pues quen todo quyere seguyr e obrar las santas virtudes del rey su abuelo ${ }^{9}$.}

Este ideal político es inseparable de la conciencia de una necesidad de renovación espiritual, basada principalmente en San Pablo y en Séneca. Márquez Villanueva señala las diversas corrientes en que se manifestó esta tendencia paulinista-senequista: el prehumanismo de Juan de Mena y de Juan de Lucena; los grandes eclesiásticos, como Alonso de Cartagena y su círculo o fray Hernando de Talavera; poetas, teólogos y juristas como Álvarez Gato, Fernando Díaz de Toledo y Juan de Torquemada. Más allá de todo esto, dicha tendencia fue también el molde en el que se conformó la orden de San Jerónimo. Independientemente de lo que pasaba en España surge además, en el norte de Europa, una fuerte corriente de renovación espiritual que cristalizaría luego, a principios del siglo siguiente, en los movimientos de erasmistas, alumbrados y luteranos, que encontrarían en España un buen caldo de cultivo entre los conversos y serían el principal objeto de las persecuciones inquisitoriales. De ahí que la creación de la Inquisición española sea inseparable del problema converso y de la división producida, antes de que dicha creación se llevara a cabo, entre aquellos conversos que la aceptaron como aplicación de la idea semítica de la inseparabilidad de la religión y la política, y aquellos otros, alejados a la vez de los judaizantes y de los inquisitoriales, que propugnaban una Iglesia libre de la estructura del poder civil, dentro de la tendencia paulinista-senequista.

En el círculo de intelectuales de la casa de Alfonso Carrillo, en los años previos a la creación de la Inquisición y de la subida al trono de

9 «Otro desir que fizo Pero Guyllén al Rey Nuestro Señor luego que rreynó e fizo paces con Aragón e Navarra», Ms. 2763, fol. 65v., vv. 37-40.

10 Francisco Márquez Villanueva, «The converso problem: An Assessmentit», en Collected Studies in Honour Américo Castro's 80 th Year, Oxford, Lincombe Lodge Research Library, 1965, pp. 327-329. 
los Reyes Católicos, parece haberse intentado teórica y prácticamente una superación de dicha división, en el sentido de mantener el statu quo medieval, en el que la Iglesia es un poder de rango espiritual trascendente por encima del civil, a la vez que lo justifica como tal, posibilitando al mismo tiempo una renovación religiosa que impida toda discriminación entre cristianos en razón de su origen y una solución para la anarquía social de la mano de una monarquía fuerte. De ahí que la Iglesia pudiera y debiera intervenir en caso necesario en los asuntos temporales, lo que explica en buena parte la actuación del prelado en la rebelión contra Enrique IV, su deposición y su sucesión. Sin embargo, parece claro que la intervención de Carrillo iba en el sentido opuesto al que prevalecería luego con el establecimiento de la Inquisición controlada por la corona, que funcionó en la práctica como un aparato represivo del poder civil frente a cualquier tipo de discrepancia, y en el que la Iglesia perdía a la vez su independencia y su función espiritual fiscalizadora de los asuntos civiles.

El papel político del arzobispo Carrillo ha sido contemplado habitualmente por la historiografía desde el punto de vista del prelado noble más o menos corrupto con excesiva ambición de poder. Sin pretender tampoco caer en su apología total, como hace Pero Guillén por motivos de interés, parece necesario revisar los móviles de su conducta o contemplarlos desde otro ángulo. La más amplia justificación del papel político de Carrilo se encuentra en la tercera suplicación de Guillén, que trata:

[a]cerca de la paz et sosiego que en estos tiempos de tanta turbación es necesaria/interpuesta por Pedro Guillen de Sebilla muy omill sierbo a su señoria ${ }^{11}$.

Y en el comienzo del prólogo justifica la obra porque:

Habiendo por verdadera dotrina, muy magnífico señor, aquel dicho de Séneca do pone que las cosas bien prevenidas non suelen ser subjetas al miedo; también mirando cómo vuestra señoría ha querido exercer e continuar aquella ciencia que se llama de la república posponiendo a la governación de ella su persona y estado, en la qual ninguno teme facer aquello que ha bien aprehendido $[. .$.$] yo, indoto [. .$.$] , osé escribir esta partecilla breve... { }^{12}$.

12 Ibid. fol. 1r, $-1 \mathrm{v}$. 
Para más adelante aludir al tema que luego detallará en los Hechos del arzobispo al referirse a la convocatoria del concilio de Aranda, que Carrillo llevó a cabo en 1473:

... Todas las cosas son de probar ante quel fierro, como face el buen médico. Ca como dice el santo Esidro en la Sinónoma, mala justicia es no perdonar la flaqueza humana, pues si a todos los estados desde vajo suelo esto pertenesce usar, en mayor y muy mayor grado a vuestra señoría conviene, así por vuestras heroicas virtudes como por la dinidad y gran perlacía y jurisdición eclesiástica so cuyas leyes non se falla poder correr el cuchillo de la temporal justicia, mas corregir y castigar por piadosas exortaciones, no fuyendo de aquella regla que la canónica dotrina permite contra aquellos que, non temerosos del bien infinito ques Dios, ocupan las preminencias e imunidades de la yglesia, de la qual solo y protector vuestra señoría se falla ${ }^{13}$.

Y en el largo poema que sigue al prólogo, fundamentación éticoreligiosa de la actuación pública de Carrillo, se aprecia en la tercera estrofa la influencia de la palinodia de Mena al frente de sus Coplas de los pecados mortales ${ }^{14}$, lo que no impide que se apoye luego en ejemplos de la antigüedad clásica, junto con otros de la Biblia o de los padres de la Iglesia, para ilustrar las cuatro virtudes cardinales, veredas o carreras a lo eterno. Entre los ejemplos de Prudencia figuran «los modernos poetas» Boccaccio, Santillana, Mena y Gómez Manrique, mientras que la Continencia «osadamente contiende con el vando de Epicuro» ${ }^{15}$. Luego pide reparación al arzobispo de los males que aquejan a Castilla:

\author{
Pues miremos los clamores \\ que penetran las estrellas, \\ los gemidos y querellas \\ de los simples labradores \\ no seamos nos los [ \\ de corazones tan duros \\ que por malos ! \\ nos mostremos tan crueles \\ ante pobres y menudos
}

Ibid. fol. $2 \mathrm{r} .-2 \mathrm{v}$.

14 «Non invoco en este paso/ciencias largas nin difusas/nin subsidio de las Musas/que abitan en parnaso/ni entiendo proceder/en melodía de canto/mas invoco a mi querer/tres personas en un ser/Padre, Hijo, Espíritu Santo» (Ibid., vv. 19-27) (Ms. 4114, fol. $5 \mathrm{v}$. )

15 Ibid. vv. $244-261$ y 378 , fols. $12 \mathrm{v} .-13 \mathrm{r}$. y $16 \mathrm{v}$. 
Mitigad por Dios la saña, el remedio non se tarde, pues paresce cómo arde este fuego por España ${ }^{16}$.

Menciona de nuevo a Gómez Manrique, esta vez como jefe militar de Carrillo, para que intervenga, y comparando el arzobispo con «Gregorio segundo», el Papa que en el siglo VIII se enfrentó al emperador iconoclasta de Bizancio, comparación que se repite en el último y más largo poema de Guillén al arzobispo ${ }^{17}$.

En el pasaje citado figura también la referencia a los labradores, pobres y menudos, en tono compasivo. Para María Rosa Lida, en la literatura de los conversos y de los tocados por el humanismo renacentista (Santillana, Mena, Valera, Lucena) asoma la simpatía hacia los humildes, labradores y menestrales ${ }^{18}$, opinión compartida por Rodríguez Puértolas en su estudio sobre Íñigo de Mendoza, en el que afirma que su carácter de converso explica en parte la defensa que hace del campesinado y su crítica del aburguesamiento de los nobles, en contra de Eiximenis, otro franciscano, quien mantiene una actitud opuesta; y cita en su apoyo a Américo Castro y Márquez Villanueva ${ }^{19}$. En el texto de Guillén, los menudos no deben ser equiparados a los campesinos, sino más bien a la clase baja ciudadana, en parte de extracción campesina, instrumento de los intereses anticonversos. La idea de virtud estoicopaulina es igualitaria, pero es dudoso calificar de rasgo converso la defensa del humilde por sí sola, sin relación con esa idea, que una parte de los intelectuales conversos compartía. En el caso de Íñigo de Mendoza, el hecho de ser franciscano, u otros factores, podrían haber influido en ello. Lo que sí parece claro es que probables conversos como Guillén no culpan a los pobres menudos sino a aquellos que los instigan provo-

16 Ibid., vv. 523-531 y 541-544, fols. 21r.-v. Las lagunas son del texto.

17 Ibid., v. 569, fol. 22v. En la última obra poética a Carrillo la referencia a Gregorio II aparece en el verso 1234: «segundo Gregorio en vida modesta».

18 María Rosa Lida, «Juan Rodríguez del Padrón, vida y obras», en Estudios sobre la literatura española del siglo XV, Madrid, Porrúa, 1977, p. 27. Este artículo había aparecido en varias partes en la Nueva Revista de Filología Hispánica entre 1952 y 1954.

19 Julio Rodríguez Puértolas, «Eiximenis y Mendoza: Literatura y sociedad en la baja Edad Media hispánica», en De la Edad Media a la edad conflictiva, Madrid, Gredos, 1972, pp. 46 ss. El trabajo procede de la Revista Valenciana de Filología, VII, 1970, pp. 139-174. 
cando la anarquía social ${ }^{20}$. Lo mismo se encuentra en el discurso que Hernando del Pulgar, otro converso, atribuye a Gómez Manrique con motivo de la revuelta de Toledo en plena guerra civil, ya muerto Enrique IV, cuando Manrique y Carrillo estaban ya situados en bandos opuestos ${ }^{21}$.

En la década de los sesenta el mesianismo que antes se había proyectado sobre Juan II y Álvaro de Luna, y luego sobre Enrique IV en los primeros años de su reinado, es trasladado, en rebelión abierta contra el rey, hacia el príncipe Alfonso, primero, coronado rey por los rebeldes en 1465, y hacia los Reyes Católicos después, tras su boda en 1469 , y es mantenido por la mayoría de los intelectuales conversos, fueran o no del círculo de Carrillo, tras la rebelión de éste contra los reyes a partir de 1475, e incluso tras la creación de la Inquisición en 1480. Márquez Villanueva destaca el caso de Hernando del Pulgar y de Álvarez Gato, quienes elogian a los reyes «hasta el punto de perjudicar sus propios intereses», y añade:

Ni en sus comienzos de cronista oficial se sentía Pulgar convencido del acierto de la Reina ni de la Inquisición, pues cuando habla de los comienzos en Sevilla recoge enseguida la noción clarísima que existía sobre la irregularidad de la norma procesal ${ }^{22}$.

Sin embargo, Pulgar había alabado en su Crónica, o al menos otorgado, la intervención de los reyes contra el Papa en el nombramiento del obispo de Cuenca en 1482. Y menciona la alegación del pontífice contra los reyes, la cual contiene ideas afines a las sustentadas por Carrillo antes de su forzado sometimiento a los monarcas:

Por el Papa se alegaba que era príncipe de la Iglesia, e tenía libertad de proveer de las iglesias de la cristiandad a quien él entendiese; e que la autoridad del Papa, y el poderío que por Dios tenía en la tierra, no era limitado, ni me-

20 En su última obra poética dirigida a Carrillo, Guillén escribe: «A vos pertenece por magnanidad /[...]/ facer los rebeldes guardar la verdad / faciéndoles guerra a sangre y a fuego / por que los menudos estén en sosiego / y torne este reyno en su libertad» (Ms. 4114, fols. 114v.-115r., vv. 1745-1752). Los rebeldes son aquí los que instigan a los menudos contra los conversos, para sacar partido de la situación.

21 Hernando del Pulgar, Crónica de los Reyes Católicos, en Crónicas de los reyes de Castilla, Madrid, B. A.E., 1878, reimpresión, Madrid, Atlas, 1953, tomo III, pp. 223-565. Para el discurso de Manrique, vid. pp. 333-336.

22 Francisco Márquez Villanueva, Investigaciones sobre Juan Álvarez Gato, Madrid, Anejos del Boletín de la Real Academia Española, 1960, 2. a ed. con apéndice, 1974, p. 297 y nota 43 . 
nos ligado para proveer de sus Iglesias a voluntad de ningún príncipe, salvo en la manera que entendiese ser servicio de Dios e bien de la Iglesia ${ }^{23}$.

Al final, los reyes triunfan, obteniendo el derecho de presentación de candidatos para los obispados, igual que habían triunfado con la Inquisición, después de que el Papa quiso revocarla, con Carrillo ya recluido en Alcalá. La contradicción y confusión en que cayeron no sólo Pulgar, sino antiguos adherentes al círculo de Carrillo, como Gómez Manrique, en su fidelidad a los Reyes Católicos, puede constatarse claramente en la Crónica de Pulgar, en el citado discurso que atribuye a Manrique, supuestamente pronunciado por éste en Toledo en 1478, cuando Carrillo pretendía que los de la ciudad, de la que Gómez había sido nombrado corregidor en 1475 , se rebelasen contra los reyes, rebelión que Manrique atajó. Scholber menciona la opinión actual de que el discurso hay que achacárselo más bien a Pulgar ${ }^{24}$, pero la atribución es lo de menos si se considera que no hace sino reflejar la opinión general entre los humanistas conversos y los antiguos miembros del círculo de Carrillo. En concreto, el discurso incluye una prevención contra el saqueo de los conversos o gente «no de linaje», basándose en la transitoriedad de toda nobleza, ya que ésta se funda en la virtud, pues:

habéis de creer que Dios fizo homes e no fizo linajes en que escogiesen. A todos fizo nobles en su nacimiento [...]. Sólo el amor de Dios, e la caridad del próximo es lo que permanece; la qual [...] le da gracia para las buenas obras que facen la verdadera fidalguía ${ }^{25}$.

En el relato de Pulgar está claro que el discurso va dirigido a los menudos o gente pobre de la ciudad:

Que por ser gentes de diversas partes venidas allí a morar, por la gran franqueza que gozan los que allí viven, deseaban escandalos por se acrecentar con robos en cibdad turbada [...]. Estos por sugestión de algunos alborotadores, en los treinta años pasados, rebelaron muchas veces contra el rey Don Juan, e contra el rey Don Enrique su fijo, e pusieron la cibdad en incendios e robos ${ }^{26}$.

Los treinta años a que alude Pulgar coinciden con el período de inseguridad para los conversos, desde el estatuto de Pedro Sarmiento, tras los motines de 1449 , lo que se confirma en el propio discurso, en

Scholberg, op. cit., p. 344.

Pulgar, op. cit., pp. 335-336.

Ibid., p. 333. 
el que se inquiere por la causa de los escándalos, que no han beneficiado sino a los alborotadores que manejan los hilos, a los que

vemos con sus faciendas crecidas, e las vuestras menguadas [...] Pienso yo que vosotros no podéis buenamente sofrir que algunos que juzgáis no ser de linaje tengan honras e oficios de gobernación de esta ciudad; porque entendéis que el defecto de la sangre les quita la habilidad de gobernar. Ansimesmo vos pesa ver riquezas en homes que, según vuestro pensamiento, no las merecen, en especial aquellos que nuevamente las ganaron ${ }^{27}$.

Contra lo cual argumenta el pasaje citado de la transitoriedad de la nobleza, de clara filiación paulina, que parece poner en duda la sociedad estamental, insistiendo en el origen noble de todos los hombres y en la necesidad de la caridad, a la vez que se hace mención del ascenso de la nueva clase:

Vemos por experiencia algunos homes destos que juzgamos nacidos de baxa sangre, forzarlos su natural inclinación a dexar los oficios baxos de los padres, e aprender sciencia, e ser grandes letrados [...] E pues que a ninguno dieron elección de linage quando nació, e a todos se dio elección de costumbres quando viven, imposible sería según razón ser el bueno privado de honra ni el malo tenerla, aunque sus primeros la hayan tenido ${ }^{28}$.

Las ideas aquí expuestas son evidentemente más propias de un letrado converso como Pulgar que de un noble como Manrique, aunque es sabido que éste abogaba por la no discriminación entre cristianos, como lo prueba, aparte de su obra, el que todavía en 1484 consiguiera de la reina Isabel el aplazamiento de la acción inquisistorial contra los conversos de Toledo ${ }^{29}$.

En sus adiciones de 1974 a su libro de 1970, Márquez Villanueva indica cómo la teoría de la sociedad estamental no es atacada en el siglo $\mathrm{XV}$ por nadie, y mucho menos por los cristianos nuevos, que veían en ella una protección contra el furor demagógico que inspira las revoluciones locales de los menudos, los cuales iban contra los conversos «en cuanto signos visibles del statu quo y de lo que hoy llamaríamos elitis-

27 Ibid., p. 335 .

28 Ibid., p. 336.

29 El hecho es mencionado ya por Antonio Paz y Meliá en la introducción a su edición del Cancionero de Gómez Manrique (Madrid, 1885) publicada en la colección de Escritores Castellanos, vol. 36, pp. XXIV-XXV, y por Menéndez Pelayo en el capítulo que dedica a Gómez Manrique en su Antología de poetas líricos (1890), cuya parte teórica reedita A. Bonilla en 1914 (Historia de la poesía castellana en la Edad Media), Madrid, V. Suárez, II, pp. 358-365). 
mo de cualquier orden (económico, intelectual y hasta religioso)», de manera que los miembros de la inteligentsia conversa:

\begin{abstract}
no luchan por reivindicaciones sociales, sino por reivindicaciones de básica dignidad humana. Lo que se pretende salvaguardar a toda costa es la noción del mérito o valor del individuo, es decir, su virtud [...]. Toda apología de la virtud individual como valor supremo constituye un acto preñado de sentido ante la marejada de estatutos y exclusiones basadas en categorías irracionales. No se olvide que la teoria estamental consideraba a defensores, oradores y labradores como manifestaciones solidarias e iguales en dignidad, como resultado que pretendían ser de normación y providencia divina. Si los cristianos nuevos se aferran de tal modo (especialmente en el XVI) al esquema de los estados es porque éstos ofrecían una ilusoria defensa ante los estatutos ${ }^{30}$.
\end{abstract}

La defensa que en el círculo de Carrillo se hace de las virtudes morales, especialmente de la caridad, va claramente en este sentido; de ahí que su postura política y religiosa pueda considerarse tradicional, en defensa de la sociedad estamental en cuanto organismo cuya razón de ser ético-religiosa impide cualquier discriminación entre cristianos viejos y nuevos. Sin embargo, Márquez Villanueva parece no tener en cuenta la contradicción latente entre esta idea de virtud, de base estoicopaulina, y el fundamento divino o providencial de la división estamental, que impide teóricamente cualquier permeabilidad entre clases basada en los simples méritos. De hecho, los estatutos no son sino la aplicación de la opinión vulgar sobre la nobleza que tanto Pulgar, en el discurso citado que atribuye a Manrique, como Diego de Valera, en su Espejo de verdadera nobleza, pretenden rebatir. Según esta vulgar opinión, dice Valera, "puede el rey fazer cavallero mas no fijodalgo» ${ }^{31}$, opinión que a la nobleza en el poder, toda con menos de cien años de antigüedad, le interesaba sobremanera fomentar, ocultando al mismo tiempo su origen bastardo o converso, como es el caso de los Reyes Católicos mismos. Y lo que éstos van a conseguir a través del pacto con la nobleza, que implica su sujeción, y del control de la Iglesia por medio de la Inquisición, es la demostración de la imposibilidad de armonizar la práctica de la virtud con el mantenimiento sin fisuras de la sociedad estamental, la cual reacciona ahora precisamente desde el poder y cierra sus

Márquez Villanueva, op. cit., p. 531.

Diego de Valera, Espejo de verdadera nobleza, en Prosistas castellanos del siglo XV, Madrid, B. A.E., 1959, ed. Mario Penna, pp. 100-101. Es significativo que Gómez Manrique tuviera en su biblioteca las obras de Valera (vid. Paz y Meliá, op. cit., vol. 39, p. 333). 
filas; y esto tanto si se considera la virtud en el mero sentido éticoreligioso, apuntando hacia una renovación espiritual, como en su aspecto más práctico, tal como aparece en Juan de Lucena, en su Tractado de los galardones, donde se asocia la virtud con el premio o la riqueza que proporciona, uno de los fundamentos ideológicos del desarrollo burgués ${ }^{32}$.

La relatividad de toda nobleza y su subordinación a la virtud o mérito, que alcanza incluso a la propia monarquía, había sido establecida en el círculo de Carrillo para justificar la rebelión abierta contra Enrique IV y su deposición en favor del príncipe Alfonso, junto con la sucesión impuesta al rey en favor de su hermana Isabel y el marido de ésta, Fernando. En su debate poético planteado en el círculo arzobispal tras la boda de éstos en 1469, Gómez Manrique dirige una pregunta a Francisco de Noya, preceptor de Fernando el Católico, a la que responden el destinatario, Pero Guillén y Rodrigo Cota. Dice Manrique:

\author{
Y lo que preguntar quiero \\ o querría si supiese, \\ si ovo reyes primero \\ que cavalleros oviese. \\ Pues el rey tiene poder \\ en las tierras tan plenario, \\ dezid si puede fazer, \\ de su poder hordinario, \\ noble de pura nobleza \\ de cualquier su natural, \\ que yo con poca sabieza \\ hago duda de lo tal ${ }^{33}$.
}

Las tres respuestas tienen una argumentación parecida: hubo antes caballeros, pues a éstos los hace la nobleza, la cual se basa en la virtud; después el rey otorga el título o nombre y la riqueza. La respuesta de Guillén es quizás la más radical:

\footnotetext{
Y sabéis quel cavallero, sin tener quien le eligiese, vino ante y postrimero elırey que título diese.
}

Ottavio Di Camillo, El humanismo castellano del siglo $X V$, Valencia, Torres, 1976, pp. 191-192.

Paz y Meliá, op. cit., vol. 39, p. 133. 


\begin{abstract}
Como no puede bolver un metal en su contrario por quen su primero ser quedara de nesçesario, assí no puede vileza gozar de sangre real, ni menos poca firmeza cobrar nonbre de leal ${ }^{34}$.
\end{abstract}

En otro orden de cosas, Hernando del Pulgar destaca la liberalidad del arzobispo Carrillo, unida a su afición a la Alquimia y a la Astrología, tanto en la Crónica citada como en el retrato que hace del prelado en sus Claros varones de Castilla, en donde achaca a esa liberalidad el que acabara su vida «pobre e adeudado» ${ }^{35}$. Es evidente la parcialidad de Pulgar al juzgar así a Carrillo, lo mismo que al caracterizarlo como traidor en su Crónica, donde culpa también a su privado Fernando de Alarcón, experto en Alquimia al parecer ${ }^{36}$.

Según Eugenio Garin, los humanistas y científicos del Renacimiento defienden la magia, la astrología y la alquimia, sin distinguirlas claramente de la actividad científica; más aún, el siglo XV recobra la magia y la alquimia en sus aspectos más positivos y útiles. Ni la alquimia ni la astrología eran tampoco incompatibles con la fe, y tuvieron incluso defensores como el franciscano Roger Bacon. Así mismo, la oposición entre Edad Media y Renacimiento no se corresponde con la existente entre irracionalismo y racionalismo, sino entre la apertura hacia la actividad transformadora, sin límites, y la cerrazón rígida de la escolástica, otra forma de racionalismo. Destaca también Garin el hecho de que en el siglo XV se consideraba como época oscura al siglo XIII y parte del $\mathrm{XIV}$, cuando dominaba el logicismo y la física aristotélica, a lo que se oponía ahora la vuelta a los auctores antiqui, esto es, a los clásicos y a los padres de la Iglesia, cuya influencia había dominado hasta el siglo XIII, todo ello unido a una nueva idea de poesía como «teología poética». De ahí también la esperanza en una renovación religiosa, pues para muchos humanistas la Edad Media, esto es, la época oscura, estaba

34 Ibid., pp. 132-139. El cancionero de Gómez Manrique, en el que aparece el debate citado, se conseva en los manuscritos 7817 de la Biblioteca Nacional de Madrid y en el 1250 del Palacio Real.

35 Hernando del Pulgar, Claros varones de Castilla, ed. J. Dominguez Bordona, 4. ${ }^{\text {a }}$ edición, Madrid, Espasa Calpe, 1969, pp. 119-120.

Pulgar, Crónica, op. cit., pp. 258-9. 
impregnada de anticristianismo por culpa de Aristóteles, lo que sirve de base a todos los movimientos de renovación espiritual, incluida la reforma protestante ${ }^{37}$.

Por su parte, P.E. Russell menciona a Toledo como centro de prácticas ocultistas durante toda la Edad Media, y se refiere al texto citado de Pulgar sobre Carrillo, destacando también que la ortodoxia religiosa cree en la realidad de la magia, la cual, aunque impregnada de elementos hebraicos, sobre todo de tipo cabalístico, era también practicada por cristianos viejos, siendo pocos los conversos acusados de hacerlo. También se refiere Russell al escepticismo de Isabel la Católica hacia la magia, no compartido por los nobles y teólogos de su corte ${ }^{38}$.

El tema astrológico aparece varias veces en las obras de Pero Guillén dedicadas a Carrillo, quizás como forma de adulación. Destaca el pasaje de la segunda suplicación al arzobispo, en el que Apolo habla del nacimiento de Guillén, «a ocho de virgo» y bajo el influjo adverso de Saturno. Pero esta mala estrella puede ser contrarrestada por el influjo favorable del primado:

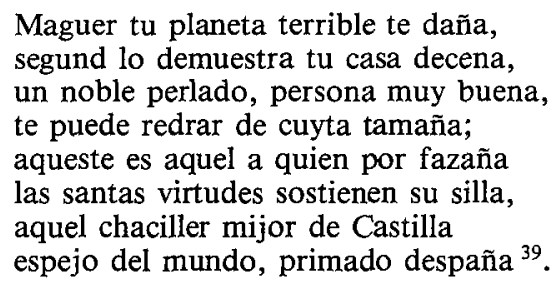

En el círculo de Carrillo es también evidente el afán de renovación religiosa junto con la vuelta a los autores antiguos y la nueva idea de poesía como «teología poética», ya presente en el círculo del marqués de Santillana. Aparece por todas partes la defensa de las tesis de San Pablo frente a Boecio, con el predominio de las virtudes morales, especialmente la caridad. Son buena muestra de ello algunos pasajes de Pero Guillén, por ejemplo en la primera suplicación al arzobispo, cuando el poeta relata al comienzo sus horas de adversidad:

37 Eugenio Garin, La revolución cultural del Renacimiento, Barcelona, Grijalbo, 1981, pp. 199-216.

38 P. E. Russell, «La magia, tema integral de La Celestina», en Temas de La Celestina y otros estudios, Barcelona, Ariel, 1978, pp. 243-276.

39 Ms. 4114, folios 24r.-48r., vv. 262 ss. y 281-288. 
Cay de mi onra en gran menospreçio, troqué por lazerya mi prosperidad; ponerme consuelo no basta Boeçio maguer a sus dichos se dé abtoridad ${ }^{40}$.

La fortuna adversa, añade luego, le quitó también a sus maestros en «sotil poesía»:

\author{
Buscando las cabsas fortuna malvada \\ por donde más daños cabsar me podría, \\ falló en mi deseo muy bien titulada \\ aquella graciosa sotil poesía, \\ y con presupuesto contrario en porfía \\ al braço valiente del fijo dalmena \\ quitóme al marqués, llevó a Juan de Mena, \\ maestros fundados de quien aprendía ${ }^{41}$.
}

Y en el prólogo a la segunda suplicación a Carrillo, cuando le pide socorro de nuevo, escribe:

Por tanto, serenísimo señor, pues la pobreza es muerte cebil y desta enfermedad aquella principal virtud teológica vos constituyó tan natural físico quanto la obra y fama en las vecinas y estrañas partes pregona vuestra señoría, mande dar orden como yo viva en mayor gloria y fama vuestra, y que sea yo un continuo miradero en quien verse pueda vuestra virtud y dignidad de perpetuo nombre ${ }^{42}$.

Lo que corresponde a la fama de magnanimidad del prelado, de la que habla Pulgar en tono negativo. A lo largo del poema, Guillén reviste a Carrillo de todas las virtudes, poniendo en lugar destacado la caridad y profetizándole la silla romana ${ }^{43}$. También Gómez Manrique, quien para Guillén «sostiene la cumbre» de la ciencia poética una vez muertos Mena y Santillana ${ }^{44}$, insiste en su Regimiento de príncipes, dirigido a los Reyes Católicos, en la superioridad de la caridad apoyándose en San Pablo ${ }^{45}$. Tanto él como Guillén no serían sino los continuadores de la línea humanístico-cristiana iniciada por sus maestros, divergente de la seguida en Italia. Russell sostiene que la idea de humanismo no puede reducirse al criterio exclusivista de los italianos y
40 Primera suplicación, vv. 25-28.
41 Ibid., vv. 57-64.
42 Ms, 4114, fol, 26v.-27r.
43 Ibid., fol 42r. y 43r., vv. 457-464 y 493-496.
44 Primera suplicación, v. 70.
45 Paz y Meliá, op. cit., vol. 39, p. 179. 
menciona a Pero Díaz de Toledo, el converso que había sido capellán de Santillana y traductor de textos clásicos en la corte de Juan II y en la del marqués, pasando luego a la casa de Carrillo. Díaz se refiere a lo que se hacía en el círculo de Santillana como studia humanitatis, algo que no hubiera sido aceptado por los humanistas italianos. Para Russell, el mecenazgo que se daba en Castilla en esta época era vital para la existencia de los pocos grandes señores que lo patrocinaban, como forma de apoyo ideológico para su causa. Al ser conscientes de su clase, no podían apoyar el humanismo de tipo italiano, que iba contra sus propios intereses. Y en el caso de los conversos, Russell se muestra de acuerdo con Américo Castro en cuanto a su influencia en la valoración de las letras como medio de ascenso social, pero sin que se arriesgaran hacia posturas radicales, permaneciendo al servicio de una nobleza protectora a la que apoyaban ideológicamente ${ }^{46}$.

Garci-Gómez llama a Santillana «gran mecenas» y a su círculo lo caracteriza como un grupo de hombres de diversos estados que se llaman amigos entre sí, componentes de lo que puede considerarse la primera generación literaria de la península:

La generación constituyó un grupo verdaderamente formidable, que los más conservadores miraban con celo y atacaban sin pudor. Los adversarios del círculo intelectual del marqués debían de ser numerosos e influyentes, a deducir por las muchas justificaciones y autodefensas a que obligaron al propio marqués y a otros con él relacionados. Entre los más conservadores se encontraban los que se oponían al estudio de los escritores paganos - para ellos, una amenaza de paganización de la cultura-, cuyos deseos se verían satisfechos cuando consiguieron llevar a cabo la quema de la biblioteca de don Enrique de Villena ${ }^{47}$.

Y menciona al anónimo traductor de la homilía de San Basilio, que Russell y Kohut atribuyen a Díaz de Toledo, como defensor de los studia humanitatis, que traduce por «estudios de la humanidad», contra los que los vituperan. Garci-Gómez se muestra contrario a la idea de Kohut ${ }^{48}$ de considerar estos estudios como mera ampliación del trivium medieval:

46 P.E. Russell, «Las armas y las letras: Para una definición del humanismo español del siglo XV», en Temas de 'La Celestina' y otros estudios, op. cit., pp. 211 ss. y 227 ss.

47 Miguel Garci-Gómez, Introducción a los Prohemios y Cartas Literarias del marqués de Santillana, Madrid, Editora Nacional, 1984, pp. 25-27.

48 Ibid., pp. 29-33, y Karl Kohut, Las teorías literarias en España y Portugal durante los siglos $X V$ y XVI, Madrid, C.S. I. C., 1973, pp. 32 y 37. 
Para el marqués de Santillana, como poeta, la actitud humanística consistía «asy en la inquisición de los fermosos poemas como en la polida orden e regla d'aquellos» [Carta-Prohemio; poema, en la terminología del escritor es la poesía de los clásicos y sus imitaciones]; como moralista, el humanismo consistía en «aver tomado todo, o la mayor parte destos Proverbios de las doctrinas e amonestamientos de otros, asy como de Platón, de Aristótiles, de Sócrates, de Virgilio, de Ovidio, de Terençio e de otros filosofos e poetas» («Prohemio a Proverbios) ${ }^{49}$.

Garci Gómez está de acuerdo con Di Camillo ${ }^{50}$ en hacer proceder a los adversarios de los estudios humanísticos de cierto sector de clérigos y teólogos, sobre todo dominicos, el mismo que había llevado a cabo la destrucción de la biblioteca de Enrique de Villena, la cual, significativamente, contenía una buena parte de libros sobre alquimia y astrología. Cita también la opinión de Elena Gascón, para quien esta quema sería una maniobra política o antisemítica ${ }^{51}$. Por su parte, Gil Fernández, al referirse también a este caso, lamentado por Juan de Mena en su Laberinto, lo relaciona con la quema de la obra De confessione, de Pedro Martínez de Osma, ordenada por el arzobispo Carrillo en $1479^{52}$. Sin embargo, no se tiene aquí en cuenta que por esta fecha Carrillo había sido ya derrotado y sometido a los Reyes Católicos y estaba confinado en Alcalá, donde tuvo lugar la condena del libro, hecha estrictamente con arreglo a los cánones de la Inquisición eclesiástica medieval, según los cuales era preceptiva la autorización papal para el proceso y la bula confirmando la condena, tal como se hizo en este caso ${ }^{53}$. Por otra parte las tesis defendidas por Martínez de Osma eran regalistas, esto es, defendía los derechos del rey sobre la Iglesia, contra Roma ${ }^{54}$, justamente lo que iba a prevalecer poco después, a partir de 1480 , con

Garci-Gómez, op. cit., p. 30.

50 Ibid., p. 33, nota 20. Di Camillo, op. cit., p. 106.

51 Ibid., nota 20, y Elena Gascón Vera, «La quema de libros de don Enrique de Villena», en Bulletin of Hispanic Studies, 56, 1979, pp. 317-324.

52 Luis Gil Fernández, Panorama social del Humanismo español, Madrid, Alhambra, 1981 , pp. 605 ss.

53 José Goñi Gaztambide, «Estado actual de los estudios sobre Pedro Martínez de Osma», en Celtiberia, 59 (1980), pp. 7-8. La historia del proceso contra Martínez de Osma es contada con todo detalle por Marcelino Menéndez Pelayo en su Historia de los Heterodoxos Españoles (1880-82): Véase, en la 3. ${ }^{\mathrm{a}}$ ed. de la B. A. C., Madrid, 1956, tomo I, pp. 566-582.

54 Bernabé Bartolomé Martínez, «Pedro Martínez de Osma, las regalías hispánicas y el P. Burriel», en Celtiberia, 59, 1980, pp. 145 ss. 
el establecimiento de la nueva Inquisición controlada por la corona, como consecuencia en buena parte del problema converso. Por todo ello, la condena de Osma encaja también en la lógica de las ideas de Carrillo, con su defensa del poder eclesiástico sobre el civil y no puede, por tanto, ponerse al mismo nivel que la quema de los libros de Villena como antecedente de lo que iba a ocurrir después, y menos aún implicar a Carrillo directamente en todo ello. Su círculo, en los años finales del reinado de Enrique IV, es precisamente continuación del humanismo cristiano practicado en el de Santillana y en ambos la figura del letrado de nuevo cuño, de origen predominantemente converso, como es el caso de Díaz de Toledo, Guillén y Mena, esto es, el letrado humanista o «gramático», frente al antiguo letrado profesional o jurista ${ }^{55}$, iría a la par con el nuevo tipo de caballero, como Santillana o Manrique, y la no incompatibilidad para éste entre las armas y las letras, consideradas éstas ahora como estudio serio y no como mero entretenimiento cortesano, propio de su clase. Tampoco habría incompatibilidad ahora para un clérigo como Díaz de Toledo entre su estado y los studia humanitatis, por lo que las fronteras entre letrado, clérigo y caballero se difuminarían en el plano intelectual y poético.

Gil Fernández culpa al establecimiento de la Inquisición de impedir un desarrollo humanístico en España, a través de un pacto entre la aristocracia, eclesiástica y seglar, y la monarquía, con el asentimiento del pueblo bajo, pues los estatutos de limpieza de sangre significaban para éste un punto de igualdad con la alcurnia nobiliaria, haciendo de la primitiva sociedad abierta del siglo XV una sociedad cerrada sometida a la burocracia inquisitorial compuesta de letrados tradicionales y de teólogos, que mantenían una concepción «medieval», es decir, escolástica, del saber, cortando el paso a los humanistas y gramáticos, auténticos letrados seglares. Indica también que el primer ataque de esos letrados tradicionales fue contra los conversos y luego contra otras desviaciones humanistas, lo que promovió una autocensura que impidió cualquier posibilidad de trabajo crítico, a la vez que supuso la derrota del nuevo tipo de letrado ${ }^{56}$. Lo mismo puede decirse de los clérigos renovadores respecto de los tradicionales o de los caballeros humanistas frente a la nobleza ignorante, progresivamente burocratizada y sometida in late medieval Castile», en Bulletin of Hispanic Studies, 62, 1985, pp. 79-94.

56 Gil Fernández, op. cit., pp. 429 ss. 
al poder real, que acabaría encontrando un refugio parcial en la lectura de libros de caballerías, como medio de evasión.

Para Lawrance, la traducción de libros éticos (Aristóteles, Cicerón, Séneca, Boecio, San Gregorio) y de los historiadores clásicos iba dirigida a mediados del siglo XV a un nuevo tipo de lector, noble o burócrata, no al letrado profesional. Los libros de historia tenían sobre todo un objetivo nobiliario, no tanto por afán humanista como para proporcionar modelos a imitar que educaran a la clase dirigente ${ }^{57}$, aspecto este que aparece en Santillana y en Gómez Manrique, quienes además aspiran a ser letrados en el nuevo sentido, cultivando una poesía seria o docta como ejercicio intelectual que requiere un estudio, algo propio de la edad madura y contrapuesto a las «cosas alegres e jocosas» del tiempo de la juventud, es decir, lo puramente trovadoresco cortesano:

¿E qué cosa es la poesia (que es nuestro vulgar gaya sçiencia llamamos), syno
un fingimiento de cosas utiles, cubiertas o veladas con muy fermosa cobertu-
ra, compuestas, distinguidas e scandidas por çierto cuento, peso e medida?
E çiertamente, muy virtuoso Señor, yerran aquellos que pensar quieren o de-
çir que solamente las tales cosas consistan e tiendan a cosas vanas e lasçivas;
que bien como los fructíferos huertos abundan e dan convenientes fructos
para todos los tiempos del año, asy los hombres bien nasçidos e doctos, a
quien estas sçiencias de arriba son infusas, usan d'aquellas e de tal exerçiçio
segund las edades. E sy por ventura las sçiencias son deseables, asy como Tu-
llio quiere, ¿quál de todas es más prestante, más noble, e más dina del hom-
bre, o quál más extensa a todas espeçies de humanidad? Ca las escuridades
e çerramientos dellas, ¿quién las abre, quién las esclaresçe, quién las demues-
tra a façe patentes syno la eloqüencia dulçe e fermosa fabla, sea metro, sea
prosa? ${ }^{58}$.

La referencia a Cicerón es considerada por Garci-Gómez como una identificación entre poesía y elocuencia, pues Santillana no haría aquí sino parafrasear al autor latino. La poesía es para el marqués la forma más elevada de elocuencia, dirigida a un fin moral utilitario:

Iñigo López de Mendoza, en su arte de madurez, cultivaría y promovería una poesía de integración humanística, que saltaba fuera de las iglesias, los palacios, las plazas y la sierras, para trepar hacia las alturas de los mitos y las peregrinas historias, como él mismo las llamaba. No era necesaria ya la verdad del suceso; el poeta tenía licencia para fingir, con tal de que su obra fuera útil ${ }^{59}$.

57 Lawrance, art. cit., pp. 81 ss.

58 Santillana, Carta-Prohemio, ed. Garci-Gómez, op. cit., pp. 84-85.

s9 Garci-Gómez, op. cit., pp. 47 y 49-53. 
Aspecto este en el que Garci-Gómez coincide con Ferrie ${ }^{60}$. Lo mismo puede aplicarse a Juan de Mena y a su Laberinto de Fortuna, donde el uso de la alegoría, según Cummins, sirve de vehículo para la exhortación moral, a la vez que considera el último y más largo poema de Pero Guillén dedicado a Carrillo como otro Laberinto escrito una generación más tarde, que reproduce el mismo esquema alegórico y tiene las mismas intenciones temáticas: reforzar el ambiente moral y unificar las facciones ${ }^{61}$. También encontramos en Pero Guillén, al final de su prohemio a La Gaya, la idea de escribir una teoría o ciencia poética en romance tomando como base a Cicerón, o mejor dicho, la Retórica nueva, ad Herennium, que se atribuía al autor latino, obra que incluye la diferenciación entre estilos y una clasificación de las figuras que procede de los estoicos:

E lo otro porque, como dixe, aunque desta çiençia gaya aya avido muchos y prudentes actores, paresçe que todos aquellos que della fablaron la pusieron el latyn y en estilo tanto elevado que pocos de los lectores pueden sacar verdaderas sentençias de sus dichos, quise yo deso que mi flaco engenio conprehender pudo escrevir algo dello en el romançe, so estilo baxo y omilde aunque no tan conpendioso como ellos lo escrivieron, con animo y voluntat que así aquellos que de vuestra muy magnífica casa a este estudio y exerçiçio se quieran dar, commo los otros estraños a cuyas manos aquesta mi obra verná, ayan o puedan aver la plática de esta çiençia y les sea así familiar que no se les pueda esconder entre los puntos y pausas de la Rretóryca Nueva de Tulio, sacándola de ally con bivo entendimiento, como aquel sea lunbre que infunde Dios en el ánima del buen varon ${ }^{62}$.

Esta idea de divulgación, para los que no saben latín, se amplía en el prólogo a los Salmos Penitenciales en donde se justifica su traducción metrificada porque:

como aquellos en nuestra santa fe toquen e a los rústicos e ynçientes su devida declaraçión denieguen ${ }^{63}$.

60 Francis Ferrie, «Aspiraciones del humanismo español del siglo XV. Revalorización del Prohemio e Carta de Santillana», en Revista de Filología Española, 57, 1974-75, pp. 195-209.

61 John G. Cummins, Introducción a la edición del Laberinto de Fortuna de Juan de Mena, Madrid, Cátedra, 1979, pp. 32-34.

62 Pero Guillén de Segovia, La Gaya Ciencia, ed. José M. ${ }^{2}$ Casas Homs, Madrid, C.S.I.C., 1962, tomo I, p. 43.

63 Pero Guillén de Segovia, Salmos Penitenciales, prólogo, Ms. 2763 de la Universidad de Salamanca, folio 44r. y Manuscrito de Oñate-Castañeda (Hougton Library, Universidad de Harvard), folio 405r. 
Idea claramente humanística que contrasta con la posterior prohibición inquisistorial de las traducciones de textos bíblicos, por lo que los Salmos sólo aparecen en la primera edición del Cancionero General de 1511, sin el prólogo, siendo suprimidos en ediciones posteriores. Se trata, además, de la única obra del autor que fue impresa.

La posición de Gómez Manrique como sucesor, con Guillén, de Mena y Santillana, es aún más clara. Una respuesta del marqués, cuando Gómez le pide un cancionero de sus obras, puede considerarse un testamento poético en favor suyo ${ }^{64}$, y Díaz de Toledo le considera también su continuador y sucesor ${ }^{65}$. Guillén mismo, en el pasaje citado antes, pide al cielo que conserve su vida por ser la cumbre de la ciencia poética tras la muerte de sus maestros ${ }^{66}$.

Gómez Manrique y Pero Guillén no harían sino continuar en la casa de Carrillo la labor de Santillana y de Mena, pero con una clara diferecia evolutiva en el sentido de conseguir un mayor sincretismo sacroprofano a través de la integración de lo paulinista y lo estoico. Tanto en Santillana como en Mena puede hacerse aún una diferenciación entre obras de inspiración clásico-pagana, como el Bías o el Laberinto, y obras meramente religiosas o cristianas, algo que en Mena llega incluso a la diferenciación entre ambas según grados, tal como ocurre en su última obra, inacabada, las Coplas contra los pecados mortales, palinodia en cuyo prohemio el autor se refiere a sus obras anteriores de inspiración pagana como una debilidad juvenil, casi a la altura de lo meramente trovadoresco, por lo que sustituye la musa pagana por la cristiana. Es significativo que en esta obra no aparezcan ya alusiones clásicas o mitológicas, tal como se promete con el cambio de musa, pero sí figuran tales alusiones en las continuaciones respectivas de Gómez Manrique y Pero Guillén. Además, es evidente el sincretismo bíblico y clásico en los Proverbios de Santillana, pero tanto en el Bías como en el Laberinto de Mena la Fortuna es aún un poder arbitrario no sometido a Dios ${ }^{67}$, o al menos el conflicto entre Fortuna y Providencia

65 Ibid., II, 237.

66

67

Paz y Melia, op. cit., I, 91-96.

Vid. supra, nota 44.

Rafael Lapesa, «Los proverbios de Santillana», en De la Edad Media a nuestros días, Madrid, Gredos, 1967, p. 111, y «El elemento moral en el Laberinto de Mena», ibid., p. 114; Juan Mendoza Negrillo, Fortuna y Providencia en la literatura castellana del siglo XV, Madrid, Real Academia Española, 1973, pp. 48 ss. 
no queda en esas obras del todo resuelto, cosa que no ocurre ya en Gómez Manrique ${ }^{68}$ ni en Pero Guillén, para quienes o bien la Fortuna queda sometida a la Providencia divina, o bien quedan las dos identificadas en sus obras más tardías, según la doctrina agustiniana de la justificación del mal y la desgracia como castigo divino por los pecados personales, de acuerdo con el misterio de los designios de Dios, que incluso permite que haya tiranos a causa de los pecados del pueblo, idea que aparece en las glosas de Díaz de Toledo a la Querella de la gobernación de Manrique ${ }^{69}$. El sincretismo de la obra tardía de Manrique y Guillén está también en consonancia con la defensa que hace Díaz de Toledo en esas glosas de los fariseos o verdaderos católicos contra los saduceos o epicúreos ${ }^{70}$, en relación igualmente con la idea de renovación religiosa de base paulinista que pueda llevar a un sincretismo real entre cristianos, aunque procedan de tradiciones diferentes, griega, gentil o judía, para emplear los mismos términos que usó el propio arzobispo Carrillo en la condena que, según Caro Baroja, hizo en 1481 de los gremios de Toledo, organizados según líneas raciales ${ }^{71}$. No es casualidad que Pero Guillén tome como modelo a Boecio y su Consolación de la Filosofía, obra claramente sincrética con elementos platónicos, aristotélicos y agustinianos, en su primera suplicación a Carrillo, donde hace una pregunta clave en relación con el conflicto entre Fortuna y Providencia:

Por qué contrariados de adversa fortuna padescen los buenos gran pena terrible los malos subidos en alta colupna ${ }^{72}$.

Y luego:

Propuesta por orden aquesta demanda que alli do se falla las almas confonde

68 Mendoza Negrillo, op. cit., pp. 122 ss.

69 Paz y Melia, op. cit., II, 251.

70 Ibid., II, 245-6.

71 Julio Caro Baroja, Los Judíos en la España moderna y contemporánea, Madrid, Istmo, 1962, III, pp. 279-281. El pasaje de Carrillo es citado también por Henry Kamen, La Inquisición Española, Barcelona, Crítica, 1967, 2. ${ }^{a}$ ed., 1979, p. 43.

72 Pero Guillén, op. cit., vv. 161-163. 
la fílosofía a quien non se esconde

del mundo movible el fin de su precio

aquella maestra del sabio Boecio

levantase presto y asy me responde ${ }^{73}$.

A pesar de que la Filosofía hace ver al autor que la pobreza es vereda de salvación y que nada queda sin premio ni castigo al final, Guillén confiesa su debilidad: "Tu loas pobreza, la qual yo denuesto" ${ }^{74}$; por lo que la Filosofía, aun desviándose de su regla, le manda dirigirse el arzobispo Carrillo, auténtico representante de la Providencia divina en este mundo:

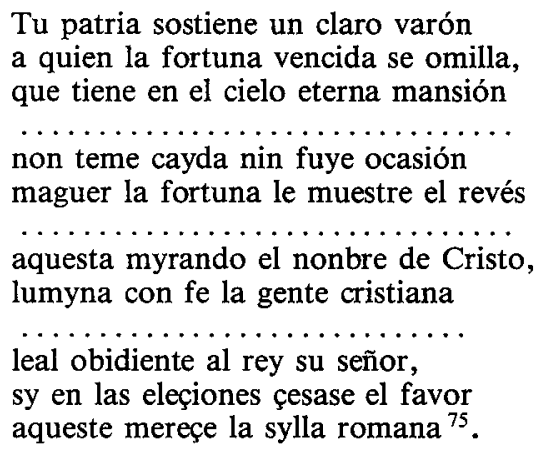

El autor, después de acumular unas cuantas referencias mitológicas, al tiempo que deja al arzobispo su nombre y dirección para que pueda encontrarle, añade:

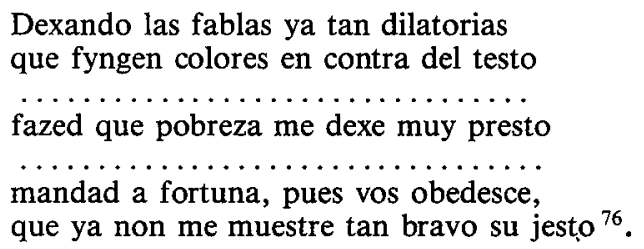

Tras de lo cual ensarta en los versos una cita de Séneca para apoyar la urgencia de su caso y concluye la obra excusándose por no llevársela al prelado en persona, pues:

Ibid., vv. 193-200.

74 Ibid., v. 291.

75 Ibid., vv. 337 ss.

76 Ibid., vv. 449 ss. 
Blüher destaca el elogio de la pobreza que hace Santillana en su Diálogo de Bías contra Fortuna, obra de base estoico-senequista que incluye también un elogio del suicidio ${ }^{78}$, lo que contrasta con la actitud de Guillén, quien conoció de verdad la pobreza y la tentación de suicidio ${ }^{79}$ y no habla teóricamente como Santillana. De ahí la diferente consideración en ambos de la misma referencia a Lucano, cuando César encuentra al pescador Amiclate viviendo en una cueva y le pide que le lleve de Grecia a Italia ${ }^{80}$. Escribe el marqués:

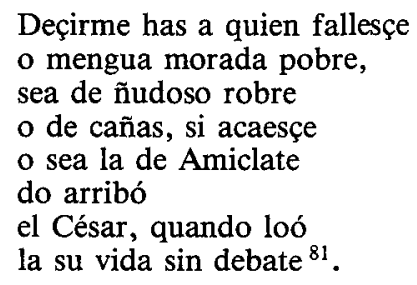

La loa de César es una adición de Santillana. Guillén, en cambio, en la primera suplicación a Carrillo, dice:

\begin{abstract}
Sy vuestra prudençia querrá saber quién es este que yaze de palmas en tierra, mandad preguntar por Pero Guyllén allende Pedraza, bien çerca la sierra, mandad preguntar adónde se ençierra la vil conpañera del triste Amiclate y adónde fortuna mayor da conbate con tantos y tales peltrechos de guerra ${ }^{82}$.
\end{abstract}

Blüher se refiere también a Pero Díaz de Toledo, al que califica de teólogo, y a su esfuerzo, como traductor de Séneca, por poner la producción de éste al servicio de la doctrina cristiana. La ética senequista, pasada por San Agustín y Boecio, es utilizada ahora para combatir la 
idea popular de Fortuna como fatum o destino ineluctable, destacando a Dios como padre que impone adversidades para probar a los hombres. La cristianización de Séneca en esta época llega hasta el extremo, según Blüher, de habérsele atribuido amistad con San Pablo e incluso su conversión al cristianismo ${ }^{83}$.

La erudición de tipo sincrético aparece continuamente en las obras doctas más largas de Guillén, sobre todo en su última época, a partir de 1463 , cuando ya formaba parte del círculo de Carrillo. Son abrumadoras las referencias directas a los autores antiguos, clásicos y padres de la Iglesia. A este respecto destaca Cummnis la familiaridad sorprendente que muestra Guillén con los autores a los que se refiere, en contraste con otros autores anteriores, como Baena o Villasandino, quienes intercalan en sus obras largas listas de autores o personajes de la antigüedad de los que no se sabe más que el nombre, y añade:

En el caso de Pero Guillén las alusiones parece que se basan en un fondo de erudición, y se refuerzan con referencias precisas a los autores clásicos y con pasajes en que imita o parafrasea las obras de sus escritores preferidos. Esta erudición nos impresionaría en las obras de un aficionado noble, de un Santillana, con su biblioteca rica en manuscritos clásicos; en un hombre pobre como Pero Guillén resulta verdaderamente asombrosa. En el empleo de sus fuentes claśicas se muestra mucho más confiado y seguro que Santillana; tampoco el mismo Juan de Mena parece haberse familiarizado mucho más que Pero Guillén con la literatura de Grecia y Roma ${ }^{84}$.

Y detalla a continuación los autores y obras más citados por Guillén en sus largos poemas doctrinales, lo que confirma su carácter de letrado humanista de nuevo cuño:

Los autores a quien alude mas frecuentemente son Séneca (De Providentia, De Clementia, De Vita Beata, Epistulae ad Lucilium, Libro de las cuatro virtudes, Tratado de las artes liberales, etc.), Aristóteles (Etica, Económica, etc.) y Boecio (De Consolatione Philosophiae); conoce las obras de Salustio (BeIlum Catilinarium), Vegecio (Epitome Rei Militaris), Cicerón, Terencio, Lucano, Homero, Platon y Xenefonte. También alude varias veces a la Biblia, y a los escritores cristianos San Agustín (De civitate Dei), San Isidoro de Sevilla (Synonymorum Libri), San Gregorio y San Ambrosio. En el prólogo de La Gaya vuelve a aludir a varios de estos autores, sobre todo a Lucano, y parafrasea a Virgilio, a Valerio Máximo y Quinto Curcio Rufo (Historia Alexandri Magni). En la mayoría de estos casos es evidente que Pedro Guillén conoce muy bien los textos a que se refiere. Aun a los autores de menor re-

Blüher, op. cit., pp. 212 ss. y 225-6.

John G. Cummins, «Pero Guillén de Segovia y el Ms. 4114», en Hispanic Review, XLI, 1973, pp. 28-29. 
nombre (Vegecio y Quinto Curcio, por ejemplo) los cita con precisión y exactitud. Entre todos estos autores, parece que los preferidos de Guillén son los hispano-romanos, Séneca y Lucano ${ }^{85}$.

No es casualidad que Guillén prefiera a los autores hispanorromanos, si se tiene en cuenta el mesianismo nacionalista de la época, antes apuntado. Cummins olvida en su lista la mención de San Jerónimo, autor este muy importante en relación con la base estoico-paulina y sincrética de las ideas predominantes en el círculo de Carrillo, pues es el primer autor cristiano que propugna la compatibilidad entre la tradición clásica y el cristianismo, transmitida luego por San Basilio y San Isidoro y que influye en el siglo XV español ${ }^{86}$. También Bertini se refiere a esto al tratar del diálogo escrito por Alfonso Ortiz, otro miembro, en su juventud, del círculo de Carrillo, en el que aparece el arzobispo como interlocutor de San Jerónimo, Sócrates, Platón, Zenón, Cicerón y Boecio. Carrillo defiende aquí la superioridad de las virtudes morales sobre las intelectuales, en especial la caridad, basándose en San Pablo ${ }^{87}$. Por otra parte, es conocida la tendencia paulinista predominantemente en la orden jerónima, a la que Carrillo apoyaba, orden que contaba con gran número de conversos ${ }^{88}$.

En suma, la erudición y el sincretismo de la poesía de Pero Guillén tienen un evidente propósito didáctico para un nuevo tipo de lector culto, noble, clérigo o letrado, con un contenido ideológico claramente referido a unos problemas concretos de la época. De ahí también la afinidad de este tipo de poesía, en cuanto a la «marcada concatenación» de loš razonamientos de las coplas y de los prólogos que preceden a algu-

85 Ibid., p. 29.

86 Sobre este tema, vid. Ernst Robert Curtius, Literatura Europea y Edad Media Latina, Mexico, F.C. E., 1955, pp. 631-633; Edgar de Bruyne, Historia de la Estética, Madrid, B. A. C., 1963, pp. 216-221; María Rosa Lida, «Perduración de la literatura antigua en Occidente», Romance Philology, V, 2-3, 1952, pp. 99-131 y «Una copla de Jorge Manrique y la tradición de Filón en la literatura española», en Estudios sobre la literatura española del siglo XV, Madrid, Porrúa, 1977, pp. 145-178 (artículo de 1942).

87 Giovanni Maria Bertini, «Un diálogo humanístico sobre la educación del príncipe don Juan», en Fernando el Católico y la cultura de su tiempo, Zaragoza, Inst. F. El Católico, 1961, pp. 52-54; comenta también el diálogo de Ortiz y el análisis de Bertini, O. Di Camillo, op. cit., pp. 261-263.

88 Américo Castro, Aspectos del vivir hispánico, Madrid, Alianza, 1970, pp. 88, 92 y 177 (1. ${ }^{\mathrm{a}}$ ed., 1949). 
nas de ellas, con «la andadura lógica y estilística del sermón» ${ }^{89}$, en tanto que inseparable de las reglas de la elocuencia y de todos los recursos retóricos de ésta, entroncada a la vez con la retórica clásica y con las artes praedicandi medievales, las cuales distinguen entre el sermón culto o divisio intra, caracterizado por el uso de las autoridades (la Biblia y los padres de la Iglesia sobre todo), compuesto principalmente en latín y dirigido a un público culto, normalmente de clérigos, y el sermón popular o divisio extra, en lengua vulgar, que utiliza exempla de toda clase tomados de fuentes variadas y alternados con sententiae o proverbios, bien deducidos de los exempla o tomados de fuente independiente ${ }^{90}$. La poesía docta amplía el uso de las autoridades de la divisio intra a la antigüedad clásica, de donde procede en buena parte su marcado carácter humanista, junto con el propósito de divulgación en romance, sin que falte a veces la palinodia, sea sincera o puramente retórica, como parece ser más bien el caso de Guillén en la tercera suplicación a Carrillo, antes citada. En otras obras utiliza probablemente como fuente de sentencias la traducción hecha por Pero Díaz de Toledo de los falsos proverbios de Séneca ${ }^{91}$. Al faltar en esta época todavía la noción moderna de autor original o creador, el auctor, aun cuando expresa opiniones suyas, ha de apoyarse necesariamente en auctoritates, pues el escritor es todavía principalmente un transmisor y un combinador o recomponedor de lo transmitido, a la vez que un commentator, haciendo inteligible el texto recopiado ${ }^{92}$. Todas estas funciones las encontramos en Pero Guillén, pero en el nuevo sentido humanista de hacer válida cualquier autoridad no incompatible con las autoridades cristianas y útil a los objetivos del autor, junto con un conocimiento directo de todas ellas fructíferamente aplicable al presente y a sus problemas:

Porque lo que en escripto se pone face lo pasado presente y trae a la imaginación los estremos y valientes fechos para que los sucesores celosos de aquellos elijan aquel camino a seguir [...] por esto se lee que fue Grecia famosa

Fernando Lázaro Carreter, «La estrofa de arte real», en Homenaje a J. M. Blecua, Madrid, Gredos, 1983, pp. 333-5.

Janet A. Chapman, «Juan Ruiz's 'learned sermon'», en Libro de Buen Amor Studies, London, Tamesis, 1970, pp. 30-32.

Blüher, op. cit., pp. 148 ss. Para la palinodia retórica de Guillén en la tercera suplicación a Carrillo, véase nota 14 .

Roland Barthes, Investigaciones retóricas. La antigua retórica, Buenos Aires, Nueva Visión, 1970, p. 25. 
entre las otras naciones de gentes por que tobo de su patria instrutos y diligentes autores que en muy elevado estilo perpetuaron sus famosos y gloriosos fechos [...] non piense vuestra señoría que esta mi indota obra solo servirá a la relación de vuestras virtuosas fazañas; mas también servirá a la exortación y amonestación de aquellos que, redrados del virtuoso y político vivir, han querido seguir contrario camino; así de un propósito salen dos efectos que son galardonar la virtud con su debido premio y tachar y reprehender los vicios con aquel denuesto que les es atribuido [...] y salen más desto otros dos presupuestos, uno que de virtudes non muera el nombre con la pasión, otro que sepan los venideros de nos lo que nos sopimos de los pasados, de que resultó venir a nuestra noticia esa diferencia que obo de los pecados de Alexandre y Julio César convertidos en vana gloria de fama temporal a los torpes inormes y fuera de toda razón cometidos por Sardanápalo ynoto ${ }^{93}$.

93 Pero Guillén, Prólogo a su última obra poética dedicada a Carrillo, Ms. 4114, folios 54r.-55v. El subrayado es nuestro. 